\title{
Speed Control of Permanent Magnet Synchronous Motor Using SVPWM Vector Control
}

\author{
Doaa AL-Mansory ${ }^{1}$, Issa Ahmed Abed ${ }^{2}$, Diyah AL-Thammer ${ }^{3}$ \\ \{doaasalihnaser@gmail.com ${ }^{1}$, issaahmedabed@stu.edu.iq ${ }^{2}$, diyahpower@stu.edu.iq ${ }^{3}$ \} \\ Engineering Technical College, Southern Technical University, Iraq ${ }^{1}{ }_{2}{ }_{3}$
}

\begin{abstract}
This article discusses how to regulate the speed of a Permanent Magnet Synchronous Motor (PMSM). Depending on the field-oriented control principle, which is among the most often used AC motor drives accessible in the industry, a new approach to regulating the PMSM using pulse width modulation of space vectors (SVPWM) is suggested. The entire framework is designed on the MATLAB /Simulink platform (vector control). The whole system, using the speed loop outside and the interior current loop, using two control loops are simulated based on synchronous motor speeds using power electronics and microelectronic technology have advanced. The AC servo device for PMSM is applied based on control methods that are used more often.
\end{abstract}

Keywords: PMSM, SVPWM, field-oriented control, controlling vector.

\section{Introduction}

In many industrial applications, the ability to control the speed of electric motors is necessary, just like robots, computer numerical control (CNC), traction engines, air conditioning, pumping systems, etc. Permanent magnet synchronous motors (PMSM) have been widely used recently increasing, substituting the Induction motor due to the requirement for greater efficiency and smaller size in an application, for example, vehicles and appliances for homes [1, 2]. This machine is now commonly used in servo systems with high-efficiency applications such as actuators in robotics and aerospace, as no external excites are provided to the rotor, reduction of damages, and highly effective PMSM. There are primarily two types of PMSM drive in the industry, one shows the distribution of sinusoidal flux in a PMSM, while the other is the distribution of trapezoidal change in a brushless DC machine [3]. Due to complexity compared to field-oriented induction motor drive control, PMSM drives are usually favored in servo systems. The principle of vector control is used in this work to achieve a linear transient response, along with decoupled regulation of the transient response of the AC threephase unit, such as the separately excited DC motor [4, 5]. The vector control-based proportional-integral (PI) control method (field-oriented control) is widespread and useful for the regulation of PMSM with an accurate mathematical model [6]. PMSM vector control was performed using the space vector pulse width modulation (SVPWM) inverter output voltage methods generation rather than a traditional sinusoidal modulation of the width of the pulse. The flux $\left(i_{d}\right)$ as well as Torque $\left(i_{q}\right)$ of the system, it is possible to function independently in the same period in this scheme [7]. The SVPWM technology ensures optimum voltage of DC input utilization and less harmonic distortion. Multilevel inverters and two-level inverters are usually known as an inverter. In contrast to the two-level inverters, one of the benefits of multilevel 
inverters is decreased harmonic distortion. Sometimes known as the control of decoupling or vectors, the field-oriented rule came in late 1960; the research field of ac drives was prominently developed in 1980 to resolve the challenges of synchronous motor drive and induction inverterfed oscillating flux and torque response. Numerous authors have modelled and simulated such a drive. The author in [8] described the modeling and simulation of a PMSM drive system that depends on FOC. The work in [9] presented a MATLAB/Simulink implementation of a vectorcontrolled PMSM drive utilizing the SVPWM method.

This paper is structured it is as follows: the PMSM basic mathematical model developed in Section II. The suggested methodology of vector control is provided in Section III. Section IV describes the implementation of the SVPWM algorithm on a systematic basis. Design of twolevel inverter in section V. Results of the simulation for section VI are discussed Section VII contains the conclusion.

\section{Proposed System}

The magnetic field is a permanent magnet. The field is excited by permanent magnets that produce sinusoidal back EMF in a synchronous motor, which is one form of AC synchronous motor. It uses a permanent magnet to generate a magnetic field. The $\mathrm{d}-\mathrm{q}$ rotor reference frame principle was used to construct the motor axis. In this model, a speed and current closed-loop control method have been used, with the SVPWM formula in the inner loop that accounts for the strong coupling, time-varying, as well as non-linearity properties, and also the PI speed controller with the outer loop to improve robustness and anti-interference efficiency.

\subsection{Mathematical Model of PMSM}

Generally, the wound rotor synchronous motor's stator is quite similar to the permanent magnet synchronous motor's stator. The main difference is that the high-performance permanent magnet PMSM rotor is constructed from new magnetic materials of rare earth with high levels of surface or rotor conductivity. The winding of the three-phase stator creates through the air gap, a rotating magnetic field. The relationship in the space between the stator and the electromagnetic field of the rotor generates electromagnetic Torque that drives the synchronization of the rotor. The following ones are the assumption in the derivation process is made [10], [11]:

- Saturation and variance of parameters are ignored.

- $\quad$ Stator windings are balanced with sinusoidal mediated EMF.

- The loss of eddy current and hysteresis is negligible.

- No current field dynamics are available.

PMSM stator voltage equations can be written as a rotating reference frame in $d, q$ with the assumptions as follows [12],[13],[14],[15],[16],[17],[18],[19],[20]:

$V_{q}=R_{s} i_{q}+\omega_{r} \lambda_{d}+\rho \lambda_{q}$

$V_{d}=R_{s} i_{d}-\omega_{r} \lambda_{q}+\rho \lambda_{d}$ 
Where, $V_{q}$ and $V_{d}$ the stator voltage is the $d, q$ reference frame, $i_{d}$ and $i_{q}$ are the $d, q$ rotating reference frame stator current in, $\lambda_{d}$ and $\lambda_{q}$ are the $d, q$ axis stator flux relation, $R_{s}$ is the winding resistance of the stator as a result of the permanent magnets., the flux linkage may be used to express as a flux linkage $\lambda_{f}$. $\rho$ : operator $\frac{d}{d t}$. Flux Linkages equations:

$\lambda_{q}=L_{q} i_{q}$

$\lambda_{d}=L_{d} i_{d}+\lambda_{f}$

Where $L_{q}$ and $L_{d}$ the inductance of the $d$ and $q$ axis stator and the rotor permanent magnet flux is $\lambda_{f}$. Substituting eqn. (3), eqn. (4) in eqn .(1), and eqn. (2) we get the voltage as:

$V_{q}=R_{s} i_{q}+\omega_{r}\left(L_{d} i_{d}+\lambda_{f}\right)+\rho L_{q} i_{q}$

$V_{d}=R_{s} i_{d}-\omega_{r} L_{q} i_{q}+\rho\left(L_{d} i_{d}+\lambda_{f}\right)$

And we arranged them in matrix format we get:

$\left[\begin{array}{l}V_{q} \\ V_{d}\end{array}\right]=\left[\begin{array}{cc}R_{s}+\rho L_{q} & \omega_{r} L_{d} \\ -\omega_{r} L_{q} & R_{s}+\rho L_{d}\end{array}\right]\left[\begin{array}{c}i_{q} \\ i_{d}\end{array}\right]=\left[\begin{array}{c}\omega_{r} \lambda_{f} \\ \rho \lambda_{f}\end{array}\right]$

In the above equation, $\omega_{r}$ is the rotor electrical speed, where $\omega_{m}$ is the mechanical rotor velocity in $\mathrm{rad} / \mathrm{sec}$,

$\omega_{m}=\omega_{r}\left(\frac{2}{p}\right)$

The formula of electromagnetic Torque generated can be written as:

$T_{e}=\frac{3}{2}\left(\frac{p}{2}\right)\left[\lambda_{f} i_{q}+\left(L_{d}-L_{q}\right) i_{d} i_{q}\right]$

If, $P$, the number of poles. By setting $i_{d}$ equal to zero and $L_{d}=L_{q}$ at in type Surface Permanent Magnet Synchronous Motor (SPMSM). The torque equation is as follows:

$T_{e}=\frac{3}{2}\left(\frac{p}{2}\right) \lambda_{f} i_{q}$

The mechanical equation of Torque for modeling of PMSM express the relationship between the electromagnetic Torque $T_{e}$, load torque $T_{l}$, and electrical speed $\omega_{r}$ as follows, the mechanical Torque equation:

$T_{e}=T_{l}+B \omega_{m}+J \frac{d \omega_{m}}{d t}$

Solving the mechanical velocity of the rotor from the equation: 
$\omega_{m}=\int\left(\frac{T_{e}-T_{l}-B \omega_{m}}{J}\right) d t$

$J$ the inertia of the rotor, $B$ the value of the coefficient of viscous friction, and $T_{l}$ the Torque of the load.

\subsection{Park and Clarke Transformations}

The amounts of $\mathrm{AC}$ motors in the three phases can be evaluated in two-phase equivalent rules $\alpha \beta$ coordinate frame for complex space vectors. They can be converted further into a relation of two-phase rotating $d q$ reference time frame invariant. The PMSM dynamic performance in the reference frame, $d q$ it can be used to describe the features of the transient and steady-state. The transformation of Clark is used to convert the quantities of three-phase $a b c$ into equivalent amounts of two stages of $\alpha \beta$ quantity as in eqn. (12). To transform the space vectors $\alpha \beta$ frame into a rotating frame that is time-invariant $d q$ frame in eqn. (13), Park converting is used. The various techniques of transformation are explained below in matrix form:

1) Transformation by Clark ( $a b c$-to- $\alpha \beta)$ :

$\left[\begin{array}{l}i_{\alpha} \\ i_{\beta}\end{array}\right]=\frac{2}{3}\left[\begin{array}{ccc}1 & \frac{-1}{2} & \frac{-1}{2} \\ 0 & \frac{\sqrt{3}}{2} & \frac{-\sqrt{3}}{2}\end{array}\right]\left[\begin{array}{l}i_{a} \\ i_{b} \\ i_{c}\end{array}\right]$

2) Transformation of Park $(\alpha \beta$-to- $d q)$ :

$\left[\begin{array}{l}i_{d} \\ i_{q}\end{array}\right]=\left[\begin{array}{cc}\cos \theta & \sin \theta \\ -\sin \theta & \cos \theta\end{array}\right]\left[\begin{array}{l}i_{\alpha} \\ i_{\beta}\end{array}\right]$

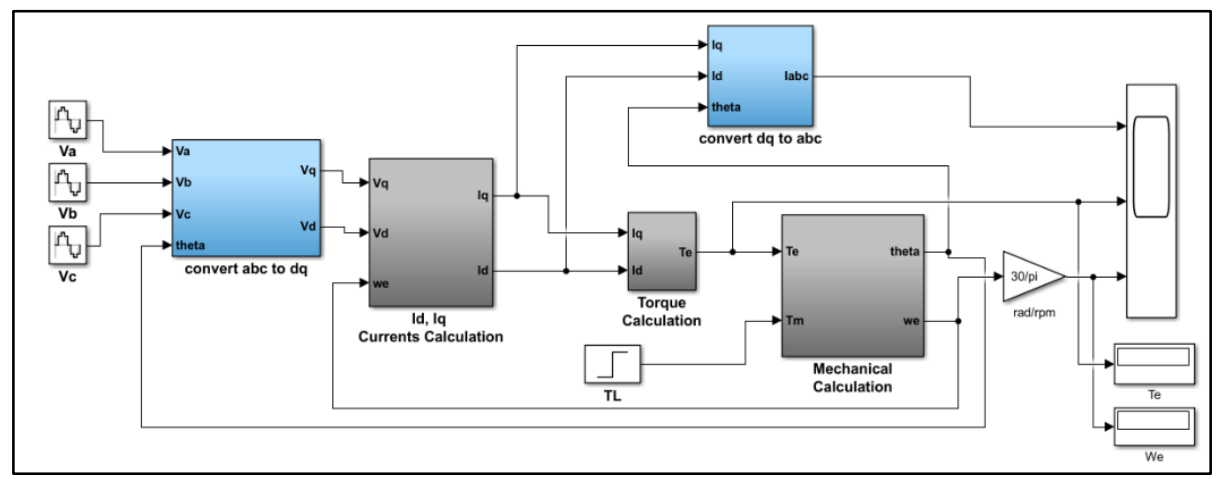

Figure 1. a) the Implementation of PMSM, MATLAB/Simulink program Simulink model with drive circuit; b) Simulink model of PMSM drive circuit 


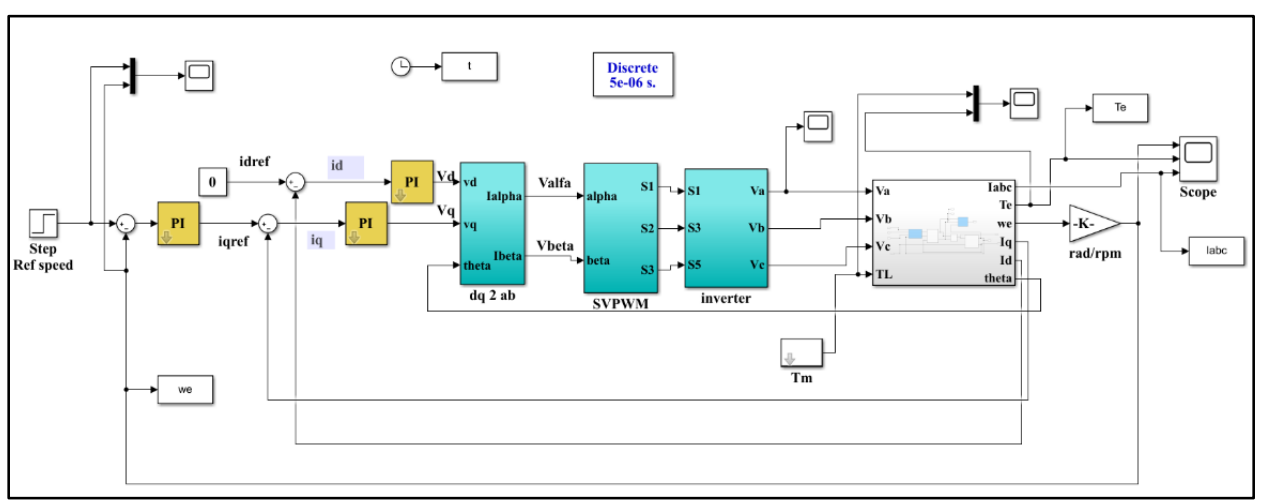

Figure 2. Simulink model of PMSM drive circuit.

\section{Vector Control Theory for PMSM}

The system of method of vector control is an intelligent method of regulating the drive to PMSM, using the field-oriented concept to regulate magnetic circuit controls of the space vector. Utilizing Park and Clarke transforms, with two orthogonal elements $i_{s q}$ and $i_{s d}, 3$-phase currents of stators are converted into two-phase currents. The regulation of vectors is supposed to separately control torque and flux. Here, $i_{s q}$ is it the component creating Torque, and $i_{s d}$ is the component making flux [21]-[22]. Therefore, there are two distinct loops for control:

1. Velocity loop: the outer circle that regulates the motor speed and produces the reference signal for the current controller with the q-axis.

2. The Current loop: the inner circle was the motor that governs the motor's flux and Torque.

For a motor drive system with maximum speed range, the speed control loop consists of a motor, an inverter, a controller that measures the discrepancy between the speed of reference and real velocity that produces an error that is fed to the controller of the PI. For the motion control system, PI controllers are commonly used. They include a proportional gain, which has results proportional to the failure input and integration for a step-change in information to make the steady-state error zero.

\section{Space Vector Technique of Pulse Width Modulation}

Modulation of Space vector pulse width (SVPWM) is a digital adjustment method that aims to produce, on average, PWM load line voltages equal to the reference load line [23]. In reality, SVPWM is just an algorithm for modulation that transforms the reference from control to phase voltage (phase to neutral) should be applied to the specified PWM modulation times/dutycycles. In the power electronics and drive systems industry, these methods of PWM switching have usually been employed. The purpose of the pulse width is modulated to provide an inverterregulated voltage output after the output voltage's harmonic content is reduced. One of the different forms of modulation techniques is Space Vector Modulation Techniques. However, SVPWM is becoming a primary method of realizing PWM due to the benefits, including.

- Lower current ripple power.

- Better use of buses.

- Lower order harmonics, along with its output voltage power, can be removed or minimized. 
The inverter can have eight space vector outputs depending on the eight possible switching combinations, of which six are active vectors (V1-V6), and two zero vectors (V0 and V7). As in the case of a regular hexagon, six sectors compose the space vector path. A maximum reachable voltage is the circle radius, i.e. $(1 / \sqrt{3}) \mathrm{Vdc}$, as seen by Fig. 3 . The distance of 60 degrees between any two non-zero vectors adjacent to them. In the SVPWM approach, the reference voltage (Vref) is a vector created through switching between one and two nearest zero vectors active space vectors, representing the three-phase AC voltage [24].

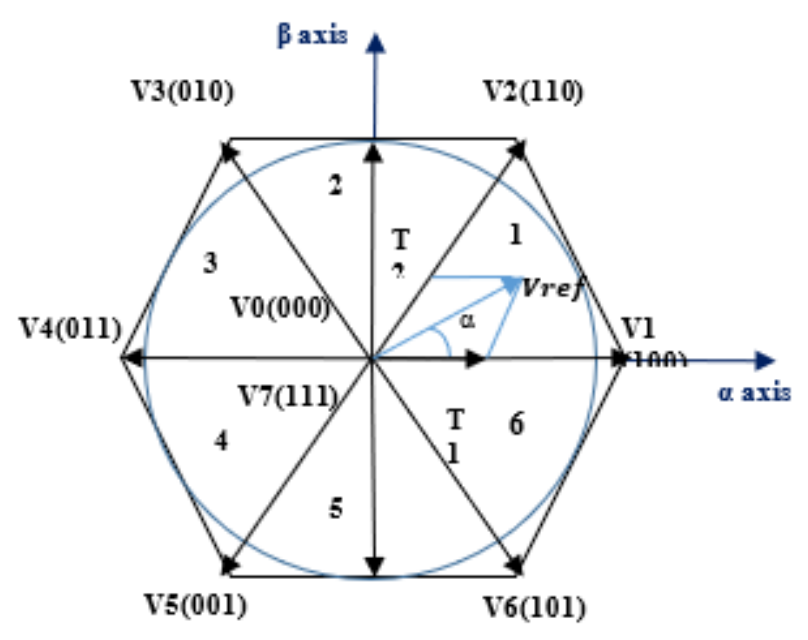

Figure 3. Basic switching vectors and six sectors for SVPWM [24].

Step1: The sector can be determined according to the relationship between $\mathrm{V} \alpha, \mathrm{V} \beta$ in each sector, andVref. Sector judgment model the following technique is used to determine the sector it is based on the expression voltage $\alpha-\beta$ coordinate for control implementation as follows: [25]

When, $V_{\beta}>0$,

After that, $A=1$, else $A=0$

$\sqrt{3} V_{\alpha}-V_{\beta}>0$,

After that, $\mathrm{B}=1$, else $\mathrm{B}=0$

$-\sqrt{3} V_{\alpha}-V_{\beta}>0$,

After that, $\mathrm{C}=1$, else $\mathrm{C}=0$

$V_{\alpha}, V_{\beta}$, they first converted from 3-phase to 2-phase stationary frame voltage.

Determination $V \alpha$ and $\mathrm{V} \beta$ from Clark's transformation as this:

$$
\left[\begin{array}{l}
V_{\alpha} \\
V_{\beta}
\end{array}\right]=\frac{2}{3}\left[\begin{array}{ccc}
1 & -\frac{1}{2} & -\frac{1}{2} \\
0 & \frac{\sqrt{3}}{2} & -\frac{\sqrt{3}}{2}
\end{array}\right]\left[\begin{array}{l}
V_{a} \\
V_{b} \\
V_{c}
\end{array}\right]
$$

Then determine $\left|\overline{V_{\text {ref }}}\right|$, and angle $\alpha$ from Fig. 4:

$\left|\overline{V_{\text {ref }}}\right|=\sqrt{V_{\alpha}^{2}+V_{\beta}^{2}} \quad ; \alpha=\tan ^{-1}\left(\frac{V_{\beta}}{V_{\alpha}}\right)=2 \pi f t$

Where $(f)$ is the fundamental frequency 


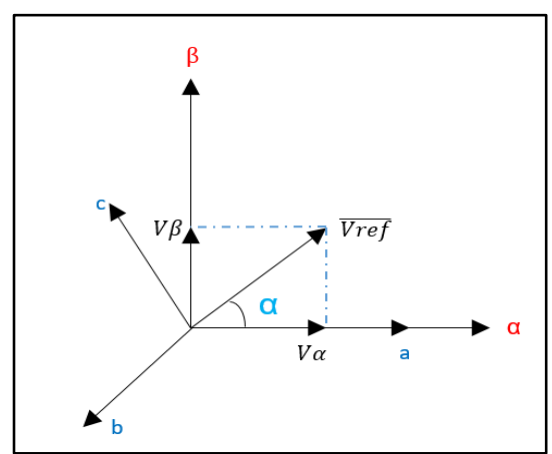

Figure 4. Reference Voltage of SVPWM for PMSM.

Step2: Vector estimation switching period T1, T2

$\mathrm{T} 1$ and $\mathrm{T} 2$ The operating time of the current sector's corresponding voltage vector. You can measure the active time as follows:

$X=\sqrt{3} \frac{T}{V_{d c}} V_{\beta}$

$Y=\frac{3}{2} \frac{T}{V_{d c}}\left(V_{\alpha}+\frac{1}{\sqrt{3}} V_{\beta}\right)$

$Z=\frac{3}{2} \frac{T}{V_{d c}}\left(\frac{1}{\sqrt{3}} V_{\beta}-V_{\alpha}\right)$

Where $\mathrm{T}$ denotes the total amount of time spent switching. It will now determine the operation time based on the data in Table 1 .

Table 1. Assessment of T1 and T2 for SVPWM.

\begin{tabular}{|l|l|l|l|l|l|l|}
\hline $\begin{array}{l}\text { The No. } \\
\text { sector }\end{array}$ & 1 & 2 & 3 & 4 & 5 & 6 \\
\hline T1 & $-\mathrm{z}$ & $\mathrm{Y}$ & $\mathrm{X}$ & $\mathrm{Z}$ & $-\mathrm{y}$ & $-\mathrm{X}$ \\
\hline $\mathrm{T} 2$ & $\mathrm{x}$ & $\mathrm{Z}$ & $-\mathrm{y}$ & $-\mathrm{x}$ & $-\mathrm{z}$ & $\mathrm{Y}$ \\
\hline
\end{tabular}

Step3: Determining the points for vector switching, the switch of the voltage vectors, the PWM symmetrical series, can be used. it can measure the vector switching points as follows:

$T_{a}=\frac{T_{0}}{4}$

$T_{b}=\frac{T_{0}}{4}+\frac{T_{1}}{2}$

$T_{c}=\frac{T_{0}}{4}+\frac{T_{1}}{2}+\frac{T_{2}}{2}$ operating times. Where $T_{0}=T-T_{1}-T_{2}$.

Now, the points for vector switching Tcm1, Tcm 2 , and Tcm 3 can be discovered in Table 2 .

Table 2. Switching with Points vector

\begin{tabular}{|l|l|l|l|l|l|l|}
\hline & \multicolumn{2}{|l|}{ Sector } & 3 & 4 & 5 & 6 \\
\hline $\begin{array}{l}\text { Point } \\
\text { switching } \\
\text { vector }\end{array}$ & 1 & 2 & 3 & & \\
\hline Tcm1 & Ta & Tb & Tc & Tc & Tb & Ta \\
\hline Tcm2 & Tb & Ta & Ta & Tb & Tc & Tc \\
\hline Tcm3 & Tc & Tc & Tb & Ta & Ta & Tb \\
\hline
\end{tabular}


Step 4: created PWM puls

Now, pulses of PWM can be generated by comparing Tcm1, Tcm2, and Tcm3 with Isosceles' triangle wave. To receive PWM2, PWM4, PWM6, it can be set on NOT service on PWM1, PWM3, and PWM5. The PWM waveform symmetrical space vector, which is used in 3-phase VSI. Below is the procedure for the design of the SVPWM method. The switching frequency (fs) of the SVPWM used in this control is $(5 \mathrm{kHz})$, and the sampling time (Ts) is $(0.0002 \mathrm{sec})$, and the dc input voltage is $200 \mathrm{v}$.

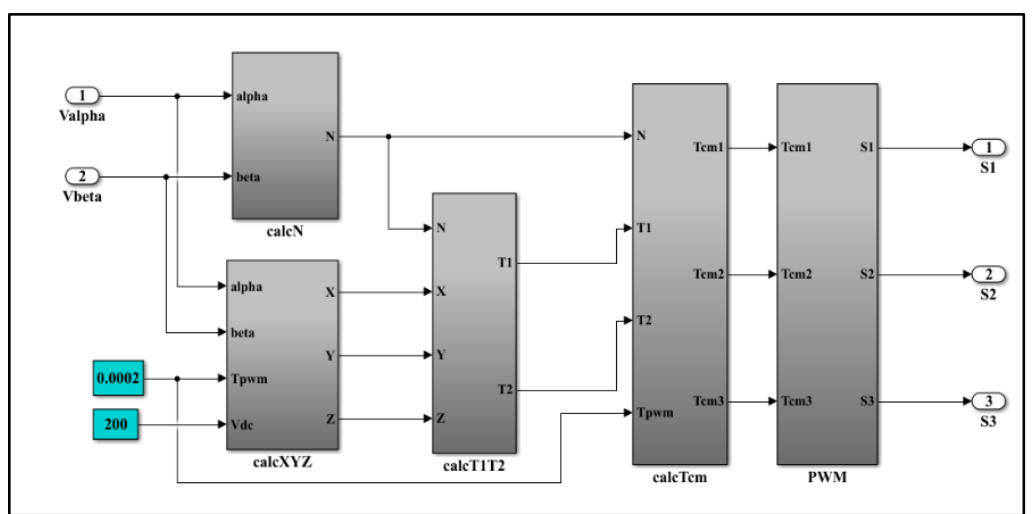

Figure 5. ign steps of SVPWM.

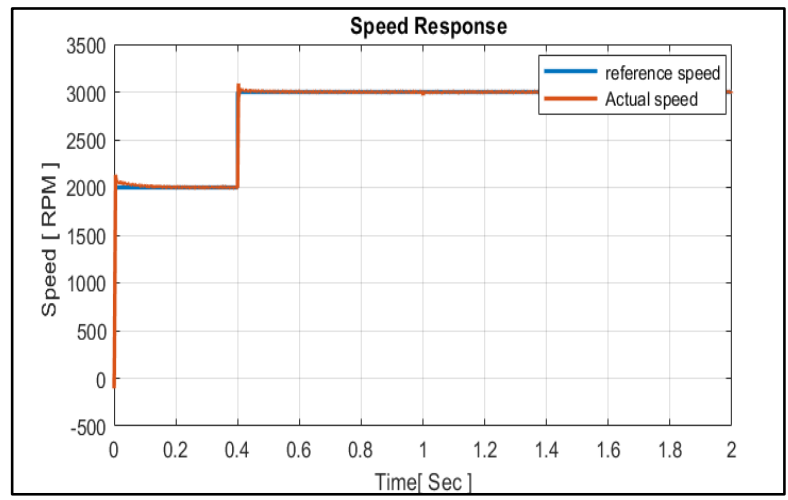

Figure 6. Speed response with reference to PMSM.

\section{Space Vector Technique of Pulse Width Modulation}

In this work, the vector control system incorporating the strategy of SVPWM for voltage inverting the supply from $\mathrm{DC}$ to $\mathrm{AC}$ is verified. A fundamental requirement with respect to the vector control system to the PMSM drive is SVPWM, which mainly a rotating vector that depends on a similar sinusoidal three-phase variable voltage. Using some examples of reference values, the motor torque and speed are regulated to check the vector control system drive for PMSM, and the findings indicate that the motor variables are almost tracking their reference. The torque and speed are displayed in Figure 6 and Figure 7 respectively. The measured motor speed of 3000-rpm constant speed, which is when any disturbance is shed the controller 
responds to the reference speed variables (step Ref). Speed and torque responses at full load torque (1.27 N.m) as illustrated below:

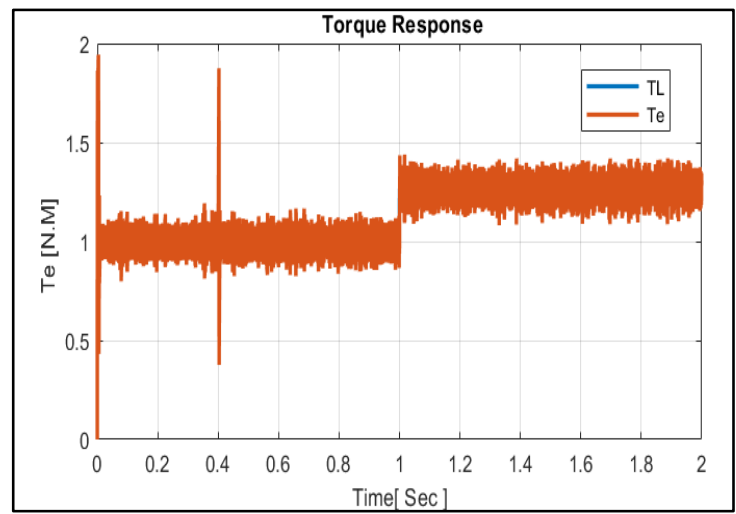

Figure 7. Electromagnetic torque with torque load.

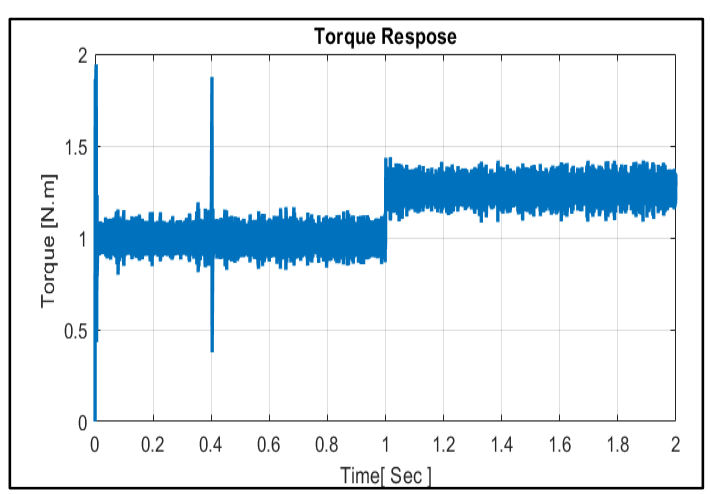

Figure 8. Three-phase stator current with PI controller.

The sinusoidal current flowing through a three-phase stator is seen in Figure.8. This value is updated during the velocity adjustment. The value of the rated phase current is used to verify the stator current's response (2.7A RMS) in table 4. That is when the load at its maximum value of the load torque TL is (1.27 N.m), at shown in Figure.9. The current value is (2.7 A RMS) at full load, and the torque response graph with the PI controller in the PMSM is show. 


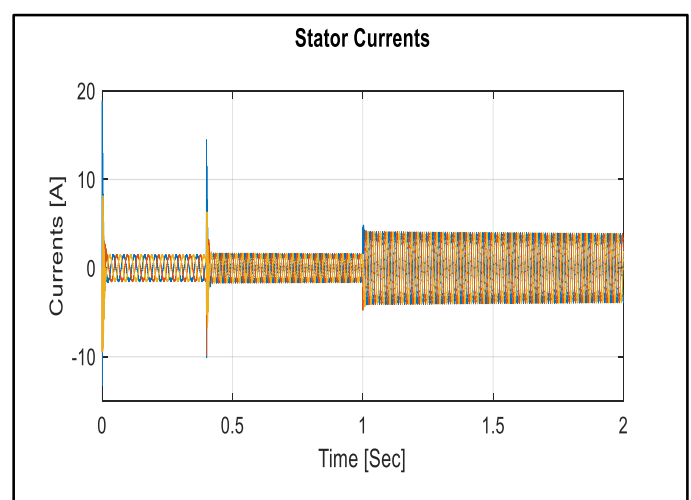

Figure 9. Torque response of the PMSM with PI controller.

A proportional-integral (PI) controller must be used to remove steady-state error [26]. This error is a result of a comparison between both the measured and reference motor speeds. This error must be equal to zero to produce tracking results as shown in Figure. 10. The settings of a traditional proportional-integral (PI) speed controller are controlled by manually adjusted to maintain the reference speed tracking [27]. Error resulting from a difference between the actual and desired speeds of the output. A proportional $K p$ parameter is utilized to reduce the time required for the rise time, and the integral parameters $K i$ are employed to reduce settling time and overshoot [28].

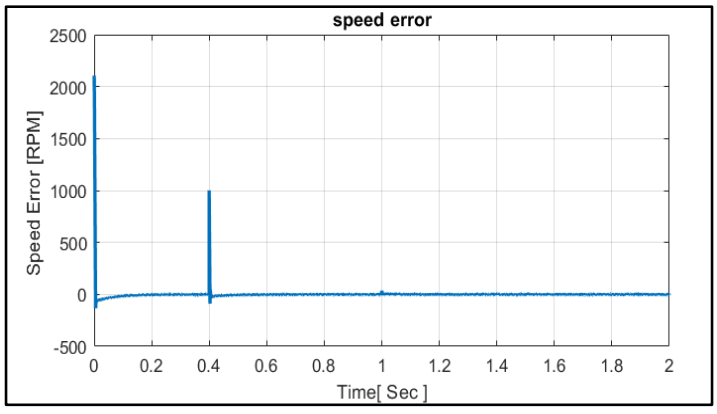

Figure 10. Error between reference speed and actual speed.

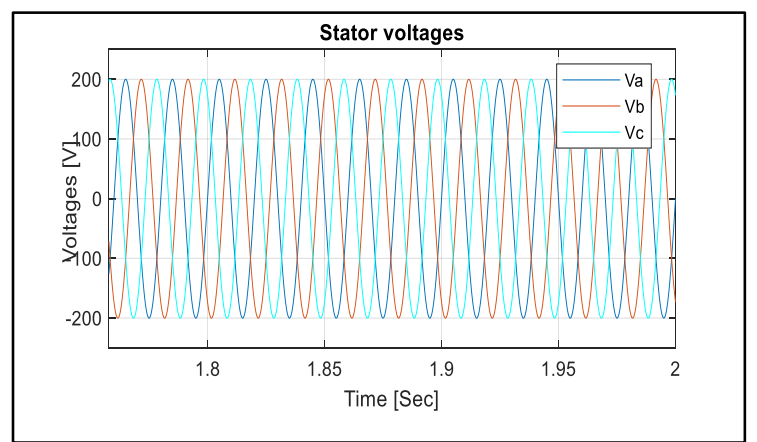

Figure 11. The stator voltages waveform. 


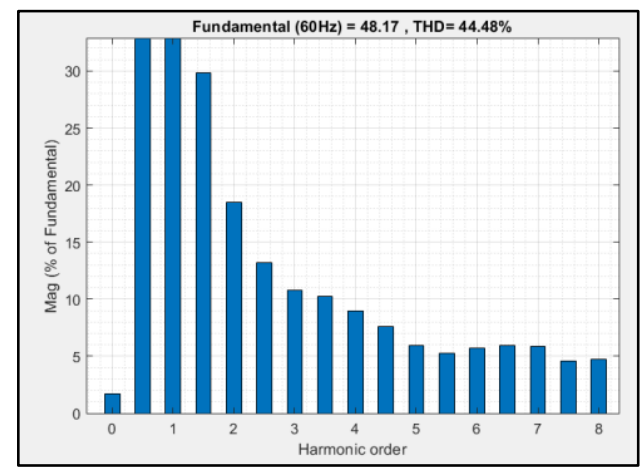

Figure 12. The total harmonics distortion for different starting time ( $0.6 \mathrm{~s}$ and $1 \mathrm{~s})$.

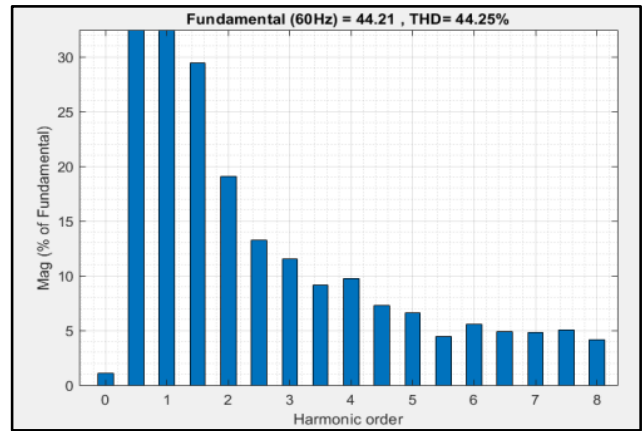

Figure 13. Percentage of Magnitude versus teh harmonic order.

Table 3. Nominal Parameters of the PMSM.

\begin{tabular}{|l|l|}
\hline \multicolumn{1}{|c|}{ Variable } & \multicolumn{1}{c|}{ Value } \\
\hline Rated current & $2.7 A_{r m s}$ \\
\hline Rated voltage & $200 V_{r m s}$ \\
\hline Speed rated & $3000 \mathrm{rpm}$ \\
\hline Torque rated & $1.27 \mathrm{~N} . \mathrm{m}$ \\
\hline Number of pairs of poles the & 4 \\
\hline Resistance to Stator winding (Rs) & $2.7 \Omega$ \\
\hline Stator inductance (L=Ld=Lq) (SPMSM) & $8.5 \mathrm{mH}$ \\
\hline Constant Torque & $0.301 \mathrm{~N} . \mathrm{m} / \mathrm{A}$ \\
\hline Linkage of flux & $0.0615 \mathrm{~Wb}$ \\
\hline Moment of Inertia & $31.69 \mathrm{e}^{-6} \mathrm{~kg} . \mathrm{m}^{2}$ \\
\hline Viscous friction B & $52.79 \mathrm{e}^{-6} \mathrm{~N} . \mathrm{m} . \mathrm{s} / \mathrm{rad}$ \\
\hline Static Nominal friction & 0.289 \\
\hline
\end{tabular}

\section{Conclusion}

Vector control schemes using the SVPWM method in the MATLAB/SIMULINK framework has been simulated and tested. For vector transformation, PMSM was decoupled into torque and excitation elements can be performed. In order to convert the three-step sinusoidal frame to reference frames and vice versa, Clark and park transformation are utilized with its inverses. The PMSM, however, has a robust nonlinear characteristic, which results in a discrepancy 
between the parameters built and the actual parameters. The simulation model of the PMSM vector control system, which is based on closed-loop flux and current in PMSM vector control systems, proposes and designs the simulation model of the PMSM vector control system using the SVPWM method in this work, which effectively simulates the complete system.

\section{References}

[1] Linares-Flores, Jesús, et al. "Robust back stepping tracking controller for low-speed PMSM positioning system design, analysis, and implementation." IEEE Transactions on industrial informatics 11.5 (2015): 1130-1141.

[2] Duc-Do, Ton, et al. " $\theta-D$ approximation technique for nonlinear optimal speed control design of surface-mounted PMSM drives." IEEE/ASME Transactions on Mechatronics 20.4 (2014): 1822-1831.

[3] Kumar Mahto, Rajesh, et al. "Vector Control of Permanent Magnet Synchronous Machine with Reduced Switch Five-Level Voltage Source Inverter." 2019 IEEE 21 st Electronics Packaging Technology Conference (EPTC). IEEE, 2019.

[4] Vindel, David, et al. "Field-oriented control of a PMSM drive system using the dSPACE controller." 2012 IEEE International Electric Vehicle Conference. IEEE, 2012.

[5] Wang, Aimeng, et al. "A new exponential reaching law of sliding mode control to improve performance of permanent magnet synchronous motor." IEEE Transactions on Magnetics 49.5 (2013): 2409-2412.

[6] Sarkar, Prasanta, et al. "SVPWM based vector control of PMSM drive in the delta domain." 2017 International Conference on Electrical, Computer, and Communication Engineering (ECCE). IEEE, 2017.

[7] Kamalaselvan, A., et al. "Modeling simulation and analysis of closed-loop speed control of the PMSM drive system." 2014 International Conference on Circuits, Power and Computing Technologies [ICCPCT-2014]. IEEE, 2014.

[8] Amin, Faisal, et al. "Modelling and simulation of field oriented control based permanent magnet synchronous motor drive system." Indonesian Journal of Electrical Engineering and Computer Science 6.2 (2017): 387-395.

[9] Saiyad Mahammad soaib, M.,"Vector controlled PMSM drive using SVPWM technique-A MATLAB/simulink implementation." Electrical, Electronics, Signals, Communication and Optimization (EESCO), 2015 International Conference. 2015.

[10] Kumar Chakraborty, Ajoy, et al. "Control of permanent magnet synchronous motor (pmsm) using vector control approach." 2016 IEEE/PES Transmission and Distribution Conference and Exposition (T\&D). IEEE, 2016.

[11] Suman, Kumari, et al. "Speed control of permanent magnet synchronous motor drive system using PI, PID, SMC and SMC plus PID controller." 2018 International Conference on Advances in Computing, Communications and Informatics (ICACCI) IEEE, 2018.

[12] Kaiqi, Zhao. "The study of an improved PI method for PMSM vector control system based On SVPWM." 2011 IEEE Industry Applications Society Annual Meeting. IEEE, 2011.

[13] Aktas, Mustafa, et al. "Comparison of DC link current and stator phase current in inverter switching faults detection of PMSM drives in HEVs." Engineering Science and Technology, an International Journal 21.4 (2018): 664-671.

[14] Amin, Faisal, et al. "Modelling and simulation of field-oriented control based permanent magnet synchronous motor drive system." Indonesian Journal of Electrical Engineering and Computer Science 6.2 (2017): 387-395.

[15] Wang, Xudong, et al. "Simulation of PMSM field-oriented control based on SVPWM." 2009 IEEE Vehicle Power and Propulsion Conference. IEEE,2009.

[16] Pandey, Richa, et al. "Multilevel Inverter Fed Permanent Magnet Synchronous Motor Drive with Constant Torque Angle Control." Advance in Electronic and Electric Engineering, Research India Publications, ISSN (2013): 22311297.

[17] Al-Khatat, Majid K., et al. "Study and compare the performance of sensor less control of PMSM drive system." Engineering and technology journal 32.10 Part (A) Engineering (2014): 2528-2547.

[18] Suman, Santosh Kumar, et al. "Novel approach of speed control of PMSM drive using neural network controller." 2016 International Conference on Electrical, Electronics, and Optimization Techniques (ICEEOT). IEEE, 2016.

[19] Dwivedi, Sanjeet, et al. "Vector Control Vs. Direct Torque Control comparative evaluation for PMSM drive." 2010 Joint International Conference on Power Electronics, Drives and Energy Systems \& 2010 Power India. IEEE, 2010.

[20] Gajanan Petkar, Sagar, et al. "A Modified Model Predictive Current Control of Permanent Magnet Synchronous Motor Drive." IEEE Transactions on Industrial Electronics (2020).

[21] Boby, Kiran, et al. "Mathematical modelling of pmsm vector control system based on SVPWM with pi controller using Matlab." International Journal of Advanced Research in Electrical, Electronics and Instrumentation Engineering 2.1(2013).

[22] Bida, Vladislav M., et al. "PMSM vector control techniques-A survey." 2018 IEEE Conference of Russian Young Researchers in Electrical and Electronic Engineering (EIConRus). IEEE, 2018. 
[23] Bhaskar Reddy, Naga, et al. "Comparison of modulation techniques for multilevel inverter fed permanent magnet synchronous motor." International Journal of Engineering Science and Technology 2.10 (2010): 5206-5214.

[24] Mohammed, Laith A., et al. "Permanent Magnet Synchronous Motor Drive Based on Maximum boost control Zsource SVPWM." Zanco Journal of Pure and Applied Sciences 31. s3 (2019): 176-181.

[25] Saiyad Mahammadsoaib, M., et al. "Vector controlled PMSM drive using SVPWM technique-A MATLAB/simulink implementation." Electrical, Electronics, Signals, Communication and Optimization (EESCO), 2015 International Conference. 2015.

[26] Utomo, Wahyu Mulyo, et al. "Speed tracking of field oriented control permanent magnet synchronous motor using neural network." International Journal of Power Electronics and Drive System (IJPEDS) 4.3 (2014): 290-298.

[27] Fadhil, Ghaith Majd, et al. "Improved Control Method for Three Phase Induction Motor Based on Optimization DTC Technique." 2020 International Conference on Electrical, Communication, and Computer Engineering (ICECCE). IEEE, 2020.

[28] Odhafa, Thaer A., et al. "Controlling of Boost Converter by Proportional Integral Controller." (2021). 